\title{
Characterization and molecular epidemiology of extensively prevalent nosocomial isolates of drug-resistant Acinetobacter spp
}

\author{
A.A. Carvalho ${ }^{1,2 *}$, L.L. Cardoso ${ }^{3}$, H.S. Nogueira ${ }^{1}$, E.V. Menezes ${ }^{1}$, \\ M.A.S. Xavier ${ }^{1,4}$, N.A.P. Barreto ${ }^{4}$, L.F. Fernandes ${ }^{5}$ and A.R.E.O. Xavier ${ }^{1,4 *}$ \\ ${ }^{1}$ Laboratório de Bioprospeção e Recursos Genéticos, Departamento de Biologia, \\ Centro de Ciências Biológicas e da Saúde, Universidade Estadual de Montes Claros, \\ Montes Claros, MG, Brasil \\ ${ }^{2}$ Unidade de Tratamento Intensivo Neonatal e Pediátrica, Hospital Santa Casa, \\ Montes Claros, MG, Brasil \\ ${ }^{3}$ Laboratório de Análises Clínicas, Hospital Santa Casa, Montes Claros, \\ MG, Brasil \\ ${ }^{4}$ Departamento de Fisiopatologia, Centro de Ciências Biológicas e da Saúde, \\ Universidade Estadual de Montes Claros, Montes Claros, MG, Brasil \\ ${ }^{5}$ Comissão de Controle de Infecção Hospitalar, Hospital Santa Casa, \\ Montes Claros, MG, Brasil \\ *These authors contributed equally to this study. \\ Corresponding author: A.R.E.O. Xavier \\ E-mail: ericsson_aerc@yahoo.com.br \\ Genet. Mol. Res. 15 (3): gmr.15038608 \\ Received March 8, 2016 \\ Accepted March 23, 2016 \\ Published August 18, 2016 \\ DOI http://dx.doi.org/10.4238/gmr.15038608
}

Copyright (C) 2016 The Authors. This is an open-access article distributed under the terms of the Creative Commons Attribution ShareAlike (CC BY-SA) 4.0 License.

ABSTRACT. Acinetobacter sp isolates deserve special attention once they have emerged globally in healthcare institutions because they display numerous intrinsic and acquired drug-resistance mechanisms. This study assessed the antibiotic susceptibility profile, the presence 
of the genetic marker $b l a_{\mathrm{OXA}-23}$, and the clonal relationship among 34 nosocomial isolates of Acinetobacter spp obtained at a hospital in southeastern Brazil. Antibiotic sensitivity analysis was performed by the standard disc-diffusion method. All isolates were found to be extensively resistant to several drugs, but sensitive to polymyxin B. A polymerase chain reaction (PCR) assay was used to detect the $b a_{\text {OXA-23 }}$ gene, which is associated with carbapenem resistance. The genetic profile and the clonal relationship among isolates were analyzed via enterobacterial repetitive intergenic consensus (ERIC)-PCR. The Acinetobacter spp were divided into four groups with 22 distinct genetic subgroups. ERIC-PCR analysis revealed the genetic diversity among isolates, which, despite having a heterogeneous profile, displayed $100 \%$ clonality among $56 \%(19 / 34)$ of them.

Key words: Acinetobacter spp; Nosocomial infections; bla $_{\text {OXA-23 }}$ gene; ERIC-PCR; Genetic diversity; Clonality

\section{INTRODUCTION}

Acinetobacter spp are Gram-negative bacteria belonging to the Moraxellaceae family. The genus Acinetobacter is widely distributed in nature (Baumann, 1968; Ferreira et al., 2011) and includes 37 different species (Peleg et al., 2008). Among these, Acinetobacter baumannii is the most clinically relevant species (Martins and Barth, 2013) and has emerged as a major problem in health institutions due to its ubiquity, difficult eradication (resistance to desiccation, chemical sanitizers, and ultraviolet) (Cherkaoui et al., 2015), and high tendency to acquire resistance to antibiotics (Peleg et al., 2008; Chang et al., 2015). This species is responsible for nosocomial infections, especially by cross transmission, and has a propensity to cause outbreaks (Khorsi et al., 2015). A. baumannii has spread globally and hence, has become one of the major causes of healthcare-associated infections (HCAIs) (Gulen et al., 2015).

With high mortality, morbidity, and hospitalization costs (Gulen et al., 2015), infections caused by multiple drug-resistant $A$. baumannii are extremely difficult to treat (de Sá Cavalcanti et al., 2013). Treating these infections has been a challenge, due to the resistance of these microorganisms to $\beta$-lactam antibiotics, which are highly-effective antimicrobial agents with low toxicity, that are widely used in the treatment of Gram-negative bacterial infections (Peleg et al., 2008; Chang et al., 2015).

Resistance to $\beta$-lactam antibiotics results mainly from the production of $\beta$-lactamases. Enzymes belonging to every class of $\beta$-lactamase from the Ambler molecular classification have been described in A. baumannii: class A, extended-Spectrum $\beta$-lactamases; class B, metallo- $\beta$-lactamases $(\mathrm{M} \beta \mathrm{L})$; class $\mathrm{C}$, Acinetobacter-derived cephalosporinases, and class $\mathrm{D}$, carbapenem-hydrolyzing class D $\beta$-lactamases (Hammoudi et al., 2015). Among these, the emergence of carbapenem resistance in A. baumannii has become a current global issue (Peleg et al., 2008; Chang et al., 2015). The molecular basis of carbapenem resistance is mainly due to the presence of Ambler class D oxacillinases, including the phylogenetic groups bla $a_{\mathrm{OXA}-23}-1$ ike, $b l a_{\text {OXA-40 }}-$ like, and $b l a_{\text {OXA-58 }}$-like oxacillinases, or to the overproduction of intrinsic enzymes of the group bla OXA-51 $_{1}$-like (Queenan and Bush, 2007; Abbott et al., 2013;), where the promoter sequences are associated with this gene, such as ISAbal (de Sá Cavalcanti et al., 2013). An

Genetics and Molecular Research 15 (3): gmr.15038608 
endemic dissemination of $A$. baumannii expressing enzymes belonging to $\beta$-lactamase Class B has also been widely reported (Peleg et al., 2008; Abbott et al., 2013).

The $b l a_{\text {OXA-23 }}$ gene, together with ISAbal, is linked to carbapenem resistance, and is the most widely disseminated among $A$. baumannii isolates worldwide, and is also the most prevalent among isolates in Brazil (Werneck et al., 2011; Fonseca et al., 2013; Pagano et al., 2013).

The objective of this study was to track the presence of the $b l a_{\text {OXA-23 }}$ gene among carbapenem-resistant nosocomial isolates of Acinetobacter spp obtained from patients admitted to a hospital in southeastern Brazil, as well as to investigate the clonal relationship among the strains involved, by characterizing the molecular epidemiological profile of the isolates.

\section{MATERIAL AND METHODS}

\section{Bacterial isolates and antibiotic sensitivity profile}

This study was performed in a 377-bed hospital, classified as a third-tier general hospital, in the southeastern region of Brazil. From November 2014 to April 2015, we obtained 34 non-repetitive clinical isolates of carbapenem-resistant Acinetobacter spp from different hospital sectors (intensive care unit, semi-intensive care unit, surgical unit, internal medicine clinic, transplantation, cardiology, and other units). Clinical isolates were obtained from samples of blood, urine, tracheal aspirate, catheter, secretions, and tissue fragments from patients. Genus-level identification of the isolates was through biochemical and enzymatic tests performed in the clinical laboratory of the hospital, according to the Clinical Laboratory Standard Institute (CLSI) guideline (Wayne, 2014). Sensitivity to several antibiotic classes was determined through the disc-diffusion test, according to the CLSI guideline. Acinetobacter sp isolates resistant to imipenem and meropenem were stored at $-20^{\circ} \mathrm{C}$ in $\mathrm{BHI}$ medium (brain heart infusion - $\mathrm{BD}^{\circledR}$ ) with $20 \%$ glycerol.

\section{DNA extraction and polymerase chain reaction (PCR) for detection of gene bla $a_{\mathrm{OXA}-23}$}

The cryopreserved isolates were reactivated by seeding in BHI medium $\left(\right.$ Laborclin $\left.^{\circledR}\right)$, and were incubated at $37^{\circ} \mathrm{C}$. After growing for $24 \mathrm{~h}$, microbial suspensions were seeded on $90 \mathrm{~mm}$-dishes with blood agar $\left(\operatorname{Laborclin}^{\mathbb{B}}\right)$ and incubated for $24 \mathrm{~h}$. Colonies were isolated from the dishes and DNA was extracted with the KAPAExtract ${ }^{\circledR}$ kit, according to the manufacturer instructions. The DNA was eluted into a final volume of $100 \mu \mathrm{L}$, quantified by $1.5 \%$ agarose gel electrophoresis, and used for PCR and enterobacterial repetitive intergenic consensus (ERIC)-PCRs. The presence of the $b l a_{\mathrm{OXA}-23}$ gene was determined by PCRs with primers OXA23F 5'-GATGTGTCATAGTATTCGTCG-3' and OXA23R 5'-TCACAACAACTAAAAGCACTG-3', resulting in a 1057-base pair amplicon (Fonseca et al., 2013). Primers were synthesized by Integrated DNA Technology, USA. Reactions took place in a mix containing 1X Taq buffer from the Kappa PCR kit, $2.5 \mathrm{mM} \mathrm{MgCl}, 1 \mu \mathrm{M}$ deoxynucleotides, $0.5 \mathrm{U}$ Kappa Taq Polymerase, $1.25 \mu \mathrm{M}$ of each primer, and $1 \mu \mathrm{L}$ (50 ng/ $\mu \mathrm{L}$ ) bacterial DNA, for a final reaction volume of $25 \mu \mathrm{L}$. Amplification conditions were as follows: an initial denaturation cycle at $95^{\circ} \mathrm{C}$ for $3 \mathrm{~min}$, followed by 35 denaturation cycles at $95^{\circ} \mathrm{C}$ for $30 \mathrm{~s}$, annealing at $55^{\circ} \mathrm{C}$ for $30 \mathrm{~s}$, extension at $72^{\circ} \mathrm{C}$ for $30 \mathrm{~s}$, and a final extension of 5 min. Amplicons were viewed on a 1.5\% agarose gel stained with ethidium bromide and were photographed. As a positive control for the PCR, we used a strain of $A$. baumannii isolated

Genetics and Molecular Research 15 (3): gmr.15038608 
from the hospital and genetically identified by a Brazilian reference laboratory (Ezequiel Dias Foundation) as $A$. baumannii coding the bla $a_{\mathrm{OXA}-23}$ gene. As a negative control, we used a strain of Escherichia coli, ATCC 25922.

\section{ERIC-PCR}

Characterization of the genetic profile and clonal relationship among the Acinetobacter sp isolates was performed through genomic DNA polymorphism analysis. The conserved primers ERIC-1 5'-TGTAAGCTCCTGGGGATTAAC-3' and ERIC-2 5'-AAGTAAGTGACTGGGGTGAGCG-3' were used in a PCR as sequences for the ERIC region described in the literature (Duan et al., 2009). Reactions took place in a mix containing $1 \mathrm{X}$ Taq buffer from the Kappa PCR kit, $2.5 \mathrm{mM} \mathrm{MgCl}_{2}, 1 \mu \mathrm{M}$ deoxynucleotides, $0.5 \mathrm{U}$ Kappa Taq polymerase, $1 \mu \mathrm{M}$ of each primer, and $2 \mu \mathrm{L}(50 \mathrm{ng} / \mu \mathrm{L})$ bacterial DNA with a final reaction volume of $50 \mu \mathrm{L}$. Amplification conditions were as follows: an initial denaturation cycle at $95^{\circ} \mathrm{C}$ for $3 \mathrm{~min}$, followed by 40 denaturation cycles at $92^{\circ} \mathrm{C}$ for $1 \mathrm{~min}$, annealing at $36^{\circ} \mathrm{C}$ for $1 \mathrm{~min}$, extension at $72^{\circ} \mathrm{C}$ for $8 \mathrm{~min}$, and a final extension of $16 \mathrm{~min}$. Amplicons were viewed on a $1.5 \%$ agarose gel stained with ethidium bromide and were photographed. Amplification profile analysis was visually performed by two observers, and was transformed into binary data in a matrix, according to the presence (1) or absence $(0)$ of bands. To determine the genetic relationship among the isolates, the matrix was subjected to the multivariate analysis "Cluster Analysis" with the complete linkage method for calculation of the Euclidean distance and generation of a dendrogram using the Minitab v.16 statistic software.

\section{Access and analysis of patient records}

With hospital authorization, and in conformity with ethical rules, the records of 34 patients from whom the extensively drug-resistant Acinetobacter spp strains had been isolated were accessed and analyzed. We looked for data regarding the principal complaint that had caused patient admission, as well as co-morbidities, age, gender, admission date, date of isolation of resistant bacteria, admission sector, and duration of hospital admission.

\section{Ethical aspects}

This study was approved by the research Ethics Committee (CEP) of the participating hospital, as well as by the CEP of Universidade Estadual de Montes Claros (No. 855.002/2014).

\section{RESULTS AND DISCUSSION}

\section{Epidemiological profile of the patients and their Acinetobacter sp isolates}

Every one of the 34 carbapenem-resistant Acinetobacter sp isolates analyzed in this study exhibited extensive drug resistance, in agreement with what has been commonly reported worldwide (Khorsi et al., 2015). The isolates were obtained from a variety of sources, such as blood $(\mathrm{N}=12)$, tracheal aspirate $(\mathrm{N}=9)$, urine $(\mathrm{N}=6)$, liquor $(\mathrm{N}=2)$, catheter $(\mathrm{N}=$ $2)$, secretions $(\mathrm{N}=2)$, and tissue fragment $(\mathrm{N}=1)$ (Table 1).

Genetics and Molecular Research 15 (3): gmr.15038608 
Table 1. Clinical characteristics of the 34 nosocomial isolates of carbapenem-resistant Acinetobacter spp.

\begin{tabular}{l|c|l|c|l|c}
\hline Gender & Total number & Source of isolation & Total number & Admission sector & Total number \\
\hline Male & $20(58.8 \%)$ & Blood & $12(35.3 \%)$ & Intensive Care Unit & $13(38.2 \%)$ \\
\hline Female & $14(41.2 \%)$ & Tracheal aspirate & $9(26.5 \%)$ & Semi-Intensive Care Unit & $6(17.6 \%)$ \\
\hline Age & & Urine & $6(17.6 \%)$ & Internal Medicine Clinic I & $2(5.9 \%)$ \\
\hline $0-20$ & 3 & Líquor & $2(5.9 \%)$ & Internal Medicine Clinic II & $6(17.6 \%)$ \\
\hline $21-50$ & 11 & Catheter tip & $2(5.9 \%)$ & Surgical Unit & $3(8.8 \%)$ \\
\hline $51-60$ & 5 & Secretion & $2(5.9 \%)$ & Cardiology & $1(3 \%)$ \\
\hline $61-70$ & 8 & Tissue fragment & $1(2.9 \%)$ & Transplantation & $1(3 \%)$ \\
\hline 71 or older & 7 & & & Other units & $2(5.9 \%)$ \\
\hline
\end{tabular}

Epidemiological analysis of the 34 patients with carbapenem-resistant Acinetobacter spp indicated that 7 were $\geq 71$ years old, 8 were between 61 and 70 years old, 5 were between 51 and 60 years old, 11 were between 21 and 50 years old, and 3 were $\leq 20$ years old, with an average age of 47.6 years $(\mathrm{SD}=21.31)$, ranging from $17-86$ years, which was comparable to what was observed in other studies (48, 54, and 53.2 years; Wisplinghoff et al., 2000; Sunenshine et al., 2007; Godoy, 2012). In the patient sample, 20 were male (58.8\%) and 14 were female (41.2\%), supporting reports by Chang et al. (2015) that males have a higher risk of infection than females. Analyzing the principal complaint related to patient admission, nine had hematological or solid neoplasms, eight had suffered trauma, five had neurological diseases, four had skin lesions (of which two were large burns), six had assorted clinical complaints (cardiac, respiratory, renal, digestive, metabolic), and two had been admitted due to post-surgery complications. The average number of days between patient admission and the date the bacteria were isolated was 27 days. As for the hospital sector to which they were admitted, 19 (55.8\%) were in the intensive care unit or in the semi-intensive care unit, eight $(23.5 \%)$ were in the internal medicine clinic, and the rest are summarized in Table 1. All of these results agree with the expected profile for patients afflicted with infection by an opportunistic microorganism of low virulence and multi-resistance to drugs, such as CRAb (carbapenem-resistant A. baumannii), that is: older patients, immunosuppressed or gravely ill, debilitated, those with co-morbidities, those with a prolonged hospital stay, and those staying in critical hospital sectors, such as the ICU.

The mortality rate by infections caused by multi-resistant $A$. baumannii is high, with different percentages having been reported in the literature (26-68\%) (Kwon et al., 2007; Sunenshine et al., 2007). However, the mortality rate attributed to these infections is hard to measure, considering that afflicted patients usually have other serious diseases and different co-morbidities that may cause a bias in the analysis (Martins and Barth, 2013; Vanegas-Múnera et al., 2014). In this study, the observed mortality rate was 50\%. Gulen et al. (2015) reported, in a controlled study, a $53 \%$ rate in a group of case patients similar to ours.

\section{Phenotypic analysis by antibiotic sensitivity profile}

In our study, the antibiotic sensitivity test performed with the Acinetobacter spp revealed a high degree of resistance to the drugs tested, characterizing them as extensively drug-resistant (Falagas and Karageorgopoulos, 2008; Manchanda et al., 2010). Of the isolates, $100 \%(34 / 34)$ were resistant to the following antibiotics: amikacin, ampicillin + sulbactam, cefepime, ceftazidime, ceftriaxone, ciprofloxacine, gentamicin, imipenem, meropenem, piperacillin + tazobactam, sulfamethoxazole + trimethoprim, and tobramycin (Table 2). Of all

Genetics and Molecular Research 15 (3): gmr.15038608 
the tested antibiotics, sensitivity was only observed to Polymyxin B. These data are equivalent to those found in Brazil by Oliveira dos Santos et al. (2014) and Guimarães (2011).

\begin{tabular}{|c|c|c|c|c|c|c|}
\hline \multirow[t]{2}{*}{ Isolate } & \multirow{2}{*}{ Isolation date } & \multirow[t]{2}{*}{ Sector ${ }^{\mathrm{a}}$} & \multirow{2}{*}{ Antibiotic resistance profile ${ }^{\mathrm{b}}$} & \multirow{2}{*}{$\begin{array}{c}\text { bla }_{\text {OXA-23 }} \\
\text { gene }\end{array}$} & \multicolumn{2}{|c|}{ Genetic profile- ERIC-PCR } \\
\hline & & & & & & \\
\hline ISO 1 & $11 / 11 / 2014$ & SICU & AMI, ASB, CPM, CAZ, CRO, CIP, GEN, IPM, MER, PPT, SXT, TOB & + & I & A \\
\hline ISO 2 & $11 / 21 / 2014$ & SU & AMI, ASB, CPM, CAZ, CRO, CIP, GEN, IPM, MER, PPT, SXT, TOB & + & II & $\mathrm{N}$ \\
\hline ISO 3 & $12 / 11 / 2014$ & SICU & AMI, ASB, CPM, CAZ, CRO, CIP, GEN, IPM, MER, PPT, SXT, TOB & + & $\mathrm{I}$ & $\mathrm{C}$ \\
\hline ISO 4 & $12 / 15 / 2014$ & ICU & AMI, ASB, CPM, CAZ, CRO, CIP, GEN, IPM, MER, PPT, SXT, TOB & + & II & $\mathrm{P}$ \\
\hline ISO 5 & $12 / 24 / 2014$ & $\mathrm{~T}$ & AMI, ASB, CPM, CAZ, CRO, CIP, GEN, IPM, MER, PPT, SXT, TOB & + & III & $\mathrm{U}$ \\
\hline ISO 6 & $12 / 26 / 2014$ & $\mathrm{O}$ & AMI, ASB, CPM, CAZ, CRO, CIP, GEN, IPM, MER, PPT, SXT, TOB & + & I & $\mathrm{H}$ \\
\hline ISO 7 & $01 / 06 / 2015$ & $\mathrm{ICU}$ & AMI, ASB, CPM, CAZ, CRO, CIP, GEN, IPM, MER, PPT, SXT, TOB & + & I & $\mathrm{J}$ \\
\hline ISO 8 & $01 / 10 / 2015$ & $\mathrm{O}$ & AMI, ASB, CPM, CAZ, CRO, CIP, GEN, IPM, MER, PPT, SXT, TOB & + & I & $\mathrm{B}$ \\
\hline ISO 9 & $01 / 11 / 2015$ & SICU & AMI, ASB, CPM, CAZ, CRO, CIP, GEN, IPM, MER, PPT, SXT, TOB & + & II & $\mathrm{R}$ \\
\hline ISO 10 & $01 / 15 / 2015$ & SU & AMI, ASB, CPM, CAZ, CRO, CIP, GEN, IPM, MER, PPT, SXT, TOB & + & $\mathrm{I}$ & B \\
\hline ISO 11 & $01 / 20 / 2015$ & $\mathrm{MC2}$ & AMI, ASB, CPM, CAZ, CRO, CIP, GEN, IPM, MER, PPT, SXT, TOB & + & II & $\mathrm{P}$ \\
\hline ISO 12 & $01 / 22 / 2015$ & SICU & AMI, ASB, CPM, CAZ, CRO, CIP, GEN, IPM, MER, PPT, SXT, TOB & + & I & A \\
\hline ISO 13 & $01 / 22 / 2015$ & ICU & AMI, ASB, CPM, CAZ, CRO, CIP, GEN, IPM, MER, PPT, SXT, TOB & + & I & I \\
\hline ISO 14 & $01 / 31 / 2015$ & SU & AMI, ASB, CPM, CAZ, CRO, CIP, GEN, IPM, MER, PPT, SXT, TOB & + & I & A \\
\hline ISO 15 & $02 / 05 / 2015$ & $\mathrm{ICU}$ & AMI, ASB, CPM, CAZ, CRO, CIP, GEN, IPM, MER, PPT, SXT, TOB & + & II & $\mathrm{S}$ \\
\hline ISO 16 & $02 / 06 / 2015$ & ICU & AMI, ASB, CPM, CAZ, CRO, CIP, GEN, IPM, MER, PPT, SXT, TOB & + & II & $\mathrm{Q}$ \\
\hline ISO 17 & $02 / 13 / 2015$ & $\mathrm{ICU}$ & AMI, ASB, CPM, CAZ, CRO, CIP, GEN, IPM, MER, PPT, SXT, TOB & + & I & $\mathrm{C}$ \\
\hline ISO 18 & $02 / 14 / 2015$ & ICU & AMI, ASB, CPM, CAZ, CRO, CIP, GEN, IPM, MER, PPT, SXT, TOB & + & II & $\mathrm{O}$ \\
\hline ISO 19 & $02 / 14 / 2015$ & MC2 & AMI, ASB, CPM, CAZ, CRO, CIP, GEN, IPM, MER, PPT, SXT, TOB & + & $\mathrm{I}$ & A \\
\hline ISO 20 & $02 / 15 / 2015$ & ICU & AMI, ASB, CPM, CAZ, CRO, CIP, GEN, IPM, MER, PPT, SXT, TOB & + & II & $\mathrm{T}$ \\
\hline ISO 21 & $02 / 25 / 2015$ & ICU & AMI, ASB, CPM, CAZ, CRO, CIP, GEN, IPM, MER, PPT, SXT, TOB & + & II & $\mathrm{T}$ \\
\hline ISO 22 & $02 / 27 / 2015$ & SICU & AMI, ASB, CPM, CAZ, CRO, CIP, GEN, IPM, MER, PPT, SXT, TOB & + & I & $\mathrm{C}$ \\
\hline ISO 23 & $03 / 16 / 2015$ & ICU & AMI, ASB, CPM, CAZ, CRO, CIP, GEN, IPM, MER, PPT, SXT, TOB & + & I & $\mathrm{K}$ \\
\hline ISO 24 & $03 / 20 / 2015$ & $\mathrm{C}$ & AMI, ASB, CPM, CAZ, CRO, CIP, GEN, IPM, MER, PPT, SXT, TOB & + & IV & $\mathrm{V}$ \\
\hline ISO 25 & $03 / 24 / 2015$ & $\mathrm{ICU}$ & AMI, ASB, CPM, CAZ, CRO, CIP, GEN, IPM, MER, PPT, SXT, TOB & + & I & $\mathrm{D}$ \\
\hline ISO 26 & $03 / 31 / 2015$ & SICU & AMI, ASB, CPM, CAZ, CRO, CIP, GEN, IPM, MER, PPT, SXT, TOB & + & I & $\mathrm{L}$ \\
\hline ISO 27 & $04 / 01 / 2015$ & $\mathrm{MC} 2$ & AMI, ASB, CPM, CAZ, CRO, CIP, GEN, IPM, MER, PPT, SXT, TOB & + & I & E \\
\hline ISO 28 & $04 / 06 / 2015$ & MC2 & AMI, ASB, CPM, CAZ, CRO, CIP, GEN, IPM, MER, PPT, SXT, TOB & + & I & G \\
\hline ISO 29 & $04 / 14 / 2015$ & MC1 & AMI, ASB, CPM, CAZ, CRO, CIP, GEN, IPM, MER, PPT, SXT, TOB & + & I & $\mathrm{F}$ \\
\hline ISO 30 & $04 / 13 / 2015$ & $\mathrm{MC} 2$ & AMI, ASB, CPM, CAZ, CRO, CIP, GEN, IPM, MER, PPT, SXT, TOB & + & I & G \\
\hline ISO 31 & $04 / 11 / 2015$ & MC2 & AMI, ASB, CPM, CAZ, CRO, CIP, GEN, IPM, MER, PPT, SXT, TOB & + & I & E \\
\hline ISO 32 & $04 / 15 / 2015$ & MC1 & AMI, ASB, CPM, CAZ, CRO, CIP, GEN, IPM, MER, PPT, SXT, TOB & + & $\mathrm{I}$ & E \\
\hline ISO 33 & $04 / 18 / 2015$ & ICU & AMI, ASB, CPM, CAZ, CRO, CIP, GEN, IPM, MER, PPT, SXT, TOB & + & I & E \\
\hline ISO 34 & $04 / 25 / 2015$ & ICU & AMI, ASB, CPM, CAZ, CRO, CIP, GEN, IPM, MER, PPT, SXT, TOB & + & I & $\mathrm{M}$ \\
\hline
\end{tabular}

\section{PCR identification of the gene $b l a_{\mathrm{OXA}-23}$}

Resistance to carbapenems in the genus Acinetobacter spp is often significantly related to the production of class D $\beta$-lactamases (OXA carbapenemases) and, less frequently, to the production of class $\mathrm{B} \beta$-lactamases (M $\mathrm{ML}$ ). Resistance related to the loss of porins may also occur, but less frequently (Martins and Barth, 2013). Of the OXA carbapenemase types, the worldwide dissemination of OXA-23 in A. baumannii is particularly noteworthy (Cherkaoui et al., 2015). Chang et al. (2015) reported in their study that most $A$. baumannii isolates from China hospital contained OXA-23-like and OXA-51-like carbapenemase genes. In Brazil, A. baumannii producing OXA-23 was detected for the first time in the city of Curitiba and spread quickly thereafter (Werneck et al., 2011; Martins et al., 2014). In this study, we tried to 
identify the presence of the gene $b l a_{\mathrm{OXA}-23}$ as a factor responsible for Acinetobacter resistance to carbapenems. As a result, all 34 isolates of carbapenem-resistant Acinetobacter spp (100\%) amplified in the PCR exhibited the expected 1057-base pair fragment corresponding to gene bla $_{\text {OXA-23 }}$, related to carbapenem resistance (Figure 1 and Table 2), a result that was expected in agreement with the literature.

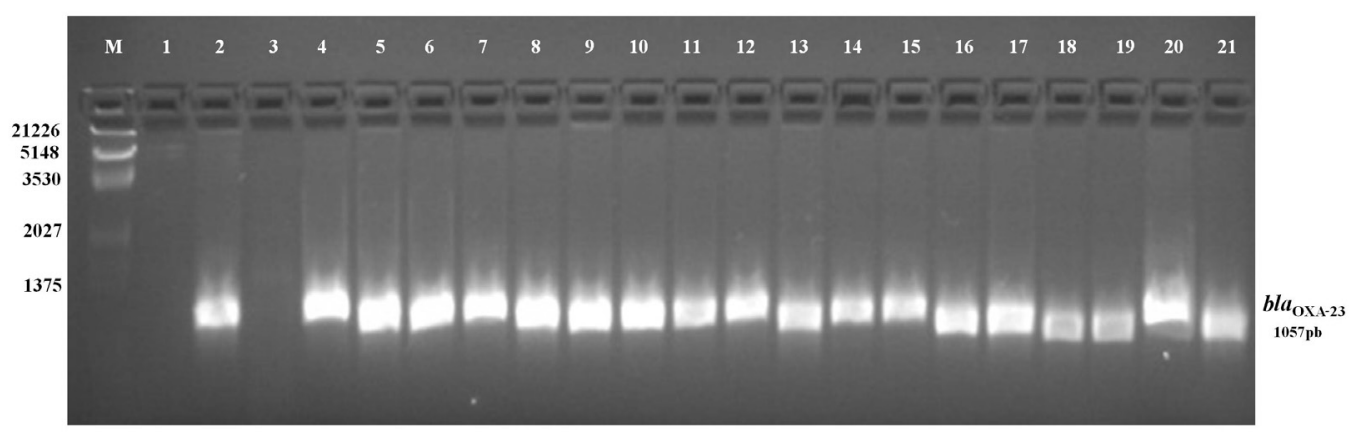

Figure 1. PCR for detection of the bla $_{\mathrm{OXA}-23}$ gene among carbapenem-resistant Acinetobacter spp nosocomial isolates on $1.5 \%$ agarose gel. Lane $M=$ Molecular mass marker Lamda EcoRI/HindIII DNA (Thermo Fisher Scientific); lane 1 = Negative control (absent DNA). lane 2 = Positive control (Acinetobacter baumannii reference strain carrying bla ${ }_{\mathrm{OXA}-23}$ gene). lane $3=$ Negative control (Escherichia coli strain BL21DE3+). lanes 4 to $21=$ Acinetobacter spp nosocomial isolates (ISO 17 to ISO 34). The size of the Lamda EcoRI/HindIII DNA marker, in base pairs, is indicated to the left. The expected 1057-base pair amplified fragment corresponding to the $b l a_{\mathrm{OXA}-23}$ gene is designated to the right of the gel.

\section{Genetic profile analysis and clonal relationship among the carbapenem-resistant Acinetobacter spp isolates carrying the bla $a_{\text {OXA-23 }}$ gene}

Genotypic analysis of the 34 isolates carrying the $b l a_{\mathrm{OXA}-23}$ gene, with the ERICPCR technique, resulting in 21 fragments of different sizes (Figure 2). For band-sharing analysis, bands in the range of 130 to 2000 base pairs were considered. The binary matrix, created by visual observation of the presence or absence of these bands, after submitting to Cluster analysis/Euclidean distance calculation, generated a dendrogram showing the clonal relationship among the isolates. The 34 isolates of carbapenem-resistant Acinetobacter spp carrying the $b l a_{\mathrm{OXA}-23}$ gene were divided into 4 different groups (I, II, III, and IV). In addition, according to the degree of similarity, it was possible to determine 22 different genotypes (A to $\mathrm{V})$, revealing a heterogeneous profile (Figure 3 and Table 2).

However, seven genotypes (IA, IB, IC, IE, IG, IIP, and IIT) had 100\% similarity among their isolates. Based on the combined analysis of the genotypes, the data regarding the sector where the patient was staying and the date of the sample collection revealed that the same strain of Acinetobacter spp was present in different patients (clone IC $=$ isolates 3 and 22; clone $\mathrm{IE}=$ isolates 27 and 31; clone $\mathrm{IG}=$ isolates 28 and 30) at the same time and place, suggesting the hypothesis that cross-transmission of the bacteria, from one patient to the other, may have happened. Also regarding the $100 \%$ similarity in genetic profile among the isolates, the presence of the same clone (clone IA = isolates 1 and 12; clone IIT = isolates 20 and 21) in patients that had been in the same sector, but during different periods, demonstrated the colonization of that hospital sector with the clones (Table 2 and Figure 3 ). 


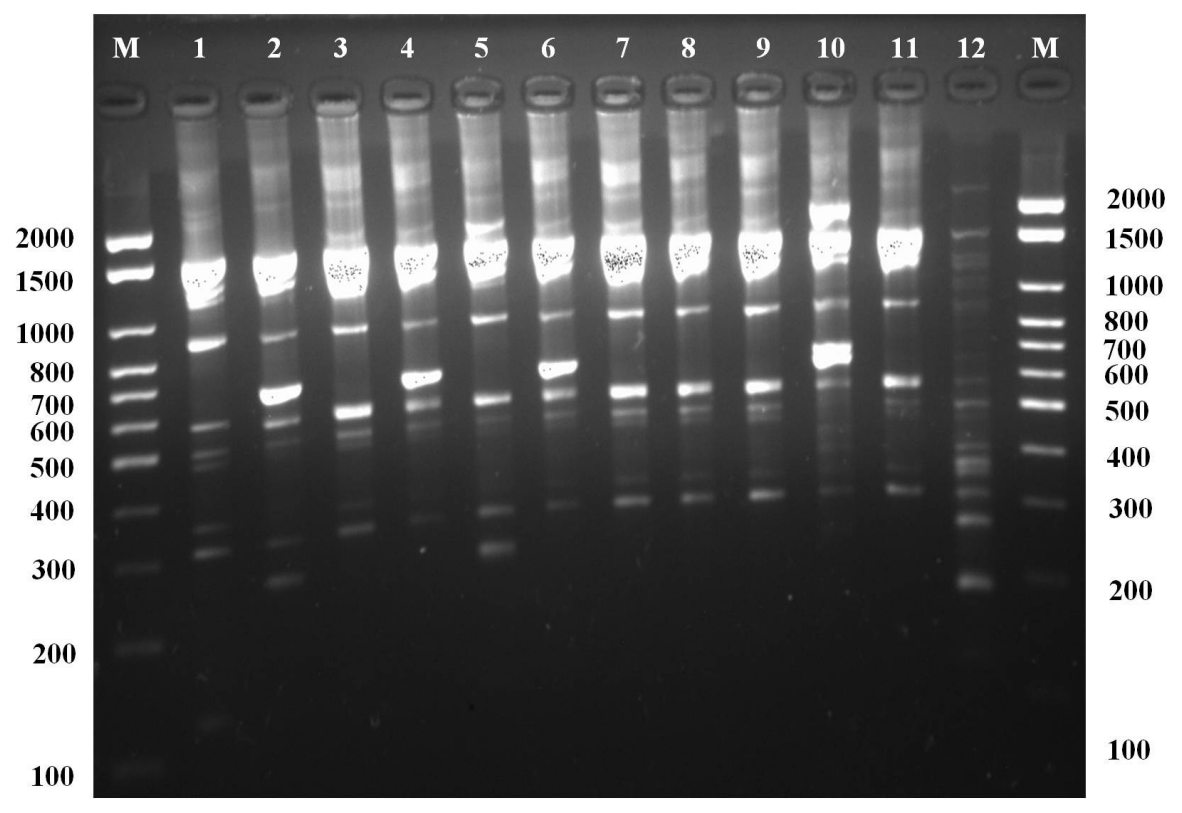

Figure 2. ERIC-PCR for determination of the genetic profile of Acinetobacter spp nosocomial isolates containing the bla $a_{\mathrm{OXA}-23}$ gene on $1.5 \%$ agarose gel. Lane $M=$ Molecular mass marker 100 base pair DNA (Norgen Biotech). Lanes 1 to $10=$ Acinetobacter spp nosocomial isolates positive for the bla ${ }_{\mathrm{OXA}-23}$ gene (ISO 25 to ISO 34). Lane 11 $=$ Isolate 33 repeated. Lane $12=$ Isolate 24 . The size of the 100 base pair DNA marker is indicated to the left and to the right of the gel.

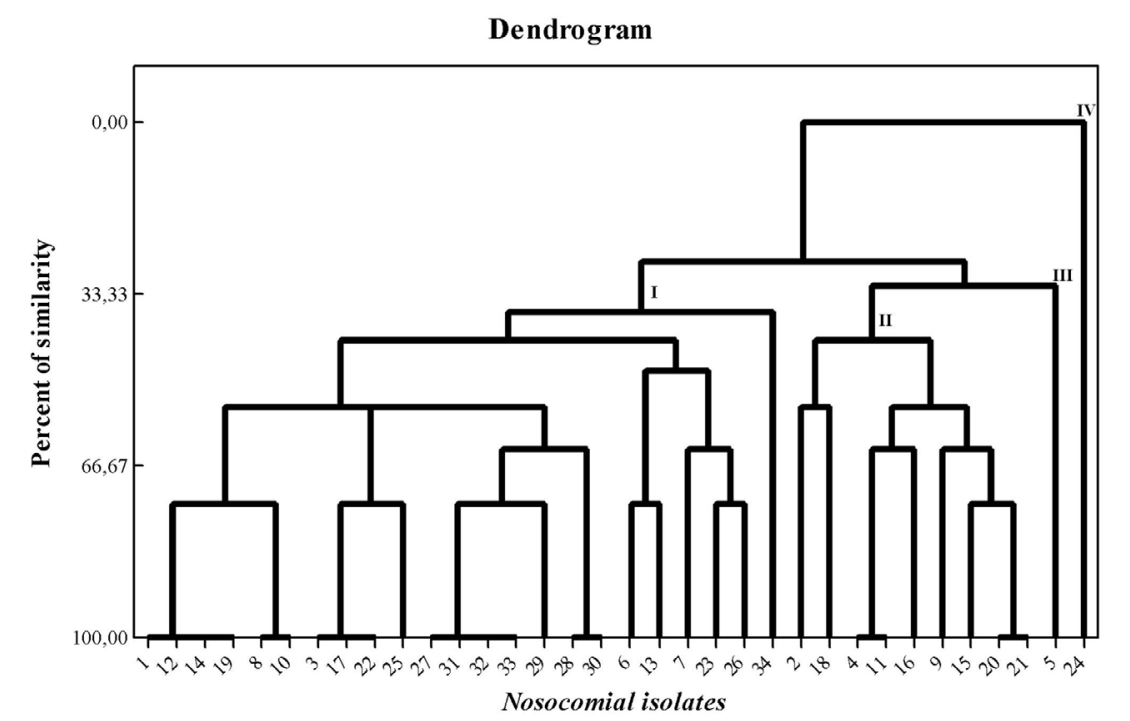

Figure 3. Dendrogram of the genetic relationship of the bla $a_{\mathrm{OXA}-23}$-positive Acinetobacter spp nosocomial isolates obtained by ERIC-PCR. Nosocomial isolates (ISO 1 to ISO 34) distributed in four groups (I, II, III, and IV) according to degree of similarity are shown. 
Profiles with 70\% similarity were found among strains of Acinetobacter spp isolated from patients that had stayed in the same sector of the hospital, in the same period of time [clone IB (isolate 10) and clone IA (isolate 14); clone IF (isolate 29) and clone IE (isolate 32); clone IIS (isolate 15) and clone IIT (isolate 20)], or in different periods of time [clone ID (isolate 25) and clone IC (isolate 17); clone IIS (isolate 15) and clone IIT (isolate 21)]. With 60\% similarity, clones IG (isolates 28 and 30) and clone IE (isolates 27 and 31), clone IIP (isolate 4) and clone IIQ (isolate 16), clone IJ (isolate 7) and clone IK (isolate 23) were present in the same place. Band analysis among these isolates revealed the presence or absence of one, two, or three discordant bands, leading us to the hypothesis of a possible mutation among the isolates.

Isolate 24, belonging to group IV, genotype IVV, was the only one which did not display a clonal relationship with the other isolates of Acinetobacter spp carrying the gene $b_{\text {OXA-23 }}$ (Table 2 and Figure 3), and displayed a band profile quite different from the others, possibly corresponding to a species of the A. baumannii-calcoaceticus complex other than A. baumannii.

Another significant data obtained from the similarity analysis was that 3 sectors of the hospital - general ICU, semi-intensive care unit, and internal medicine clinic, each with very peculiar characteristics, both in relation to the patient profile as well as the physical structure - were the likely places of acquisition/transmission of the bacteria for most of the patients.

Considering the diversity of the resistance genes, and the easy dissemination of $A$. baumannii, the study of the local epidemiology of isolates of Acinetobacter spp is of great importance to guide epidemiological control and to determine the best treatment, preventing intra-, or even inter-hospital dissemination of these microorganisms (Ferreira et al., 2011). In this regard, the ERIC-PCR technique emerges as a fast and low-cost alternative method that shows good results for genetic characterization of Acinetobacter spp isolates (Ferreira et al., 2011).

In conclusion, this study reported the high prevalence of the gene $b l a_{\mathrm{OXA}-23}$ among nosocomial clinic isolates of extensively drug-resistant Acinetobacter spp in a hospital in the southeastern region of Brazil. ERIC-PCR analysis allowed us to ascertain the genetic diversity among the isolates, which, albeit with a heterogeneous profile, in some cases displayed $100 \%$ clonality. This data lead us to important considerations, as well as to adopt intervention measures at several levels. In revealing cross transmission and environmental colonization in some of the hospital units, they indicate the need to review and improve actions to prevent HCAIs: precautions regarding contact and isolation of patients to reduce the opportunities for cross transmission; improvement of the physical environment and clinical practices, based on adherence to best practices for control of hospital infections; identification of germ sources; and assessment of the quality of the methods adopted for environmental hygiene.

At the same time, the heterogeneous profile found in the samples, indicating the presence of several strains in the hospital environment, suggests a situation of high selective pressure through the use of antibiotics, and therefore, the need to curtail inappropriate use of antibiotics. In that sense, key elements for controlling their use may be: differentiating between colonization and infection, and limiting treatment to cases of infection; and knowledge of the local sensitivity profile of the microorganisms to antibiotics, in order to rationalize their use.

\section{Conflicts of interest}

The authors declare no conflict of interest.

Genetics and Molecular Research 15 (3): gmr.15038608 


\section{ACKNOWLEDGMENTS}

The authors thank the Bioprospecting and Genetic Resources Laboratory, UNIMONTES, Santa Casa Brazilian Hospital, and Fundação de Apoio à Pesquisa do Estado de Minas Gerais (FAPEMIG) for supporting this study.

\section{REFERENCES}

Abbott I, Cerqueira GM, Bhuiyan S and Peleg AY (2013). Carbapenem resistance in Acinetobacter baumannii: laboratory challenges, mechanistic insights and therapeutic strategies. Expert Rev. Anti Infect. Ther. 11: 395-409. http://dx.doi. org/10.1586/eri.13.21

Baumann P (1968). Isolation of Acinetobacter from soil and water. J. Bacteriol. 96: 39-42.

Chang Y, Luan G, Xu Y, Wang Y, et al. (2015). Characterization of carbapenem-resistant Acinetobacter baumannii isolates in a Chinese teaching hospital. Front. Microbiol. 6: 910. http://dx.doi.org/10.3389/fmicb.2015.00910

Cherkaoui A, Emonet S, Renzi G and Schrenzel J (2015). Characteristics of multidrug-resistant Acinetobacter baumannii strains isolated in Geneva during colonization or infection. Ann. Clin. Microbiol. Antimicrob. 14: 42. http://dx.doi. org/10.1186/s12941-015-0103-3

de Sá Cavalcanti FL, Almeida AC, Vilela MA, de Morais Junior MA, et al. (2013). Emergence of extensively drugresistant OXA-72-producing Acinetobacter baumannii in Recife, Brazil: risk of clonal dissemination? Diagn. Microbiol. Infect. Dis. 77: 250-251. http://dx.doi.org/10.1016/j.diagmicrobio.2013.07.022

Duan H, Chai T, Liu J, Zhang X, et al. (2009). Source identification of airborne Escherichia coli of swine house surroundings using ERIC-PCR and REP-PCR. Environ. Res. 109: 511-517. http://dx.doi.org/10.1016/j.envres.2009.02.014

Falagas ME and Karageorgopoulos DE (2008). Pandrug resistance (PDR), extensive drug resistance (XDR), and multidrug resistance (MDR) among Gram-negative bacilli: need for international harmonization in terminology. Clin. Infect. Dis. 46: 1121-1122, author reply 1122. http://dx.doi.org/10.1086/528867

Ferreira AE, Marchetti DP, Cunha GR, Oliveira LM, et al. (2011). Molecular characterization of clinical multiresistant isolates of Acinetobacter sp. from hospitals in Porto Alegre, State of Rio Grande do Sul, Brazil. Rev. Soc. Bras. Med. Trop. 44: 725-730. http://dx.doi.org/10.1590/S0037-86822011000600014

Fonseca EL, Scheidegger E, Freitas FS, Cipriano R, et al. (2013). Carbapenem-resistant Acinetobacter baumannii from Brazil: role of $c a r O$ alleles expression and bla $_{\text {OXA-23 }}$ gene. BMC Microbiol. 13: 245. http://dx.doi.org/10.1186/1471$\underline{2180-13-245}$

Godoy CSM (2012). Infecções por Acinetobacter baumannii em adultos admitidos em Unidades de Terapia Intensiva (UTIs) de Goiânia e Aparecida de Goiânia. Dissertação de Mestrado apresentada à Universidade Federal de Goiás/ Programa de Pós-graduação em Medicina Tropical e Saúde Pública, 85.

Guimarães MP (2011). Ocorrência de Acinetobacter baumannii resistente aos carbapenêmicos em pneumonias associadas a ventilação mecânica em uma unidade de terapia intensiva de adultos mista de um hospital universitário brasileiro: fatores de risco e prognóstico. Dissertação de Mestrado apresentada à Universidade Federal de Uberlândia/Programa de Pós-graduação em Imunologia e Parasitologia Aplicadas, 51.

Gulen TA, Guner R, Celikbilek N, Keske S, et al. (2015). Clinical importance and cost of bacteremia caused by nosocomial multi drug resistant Acinetobacter baumannii. Int. J. Infect. Dis. 38: 32-35.

Hammoudi D, Moubareck CA, Hakime N, Houmani M, et al. (2015). Spread of imipenem-resistant Acinetobacter baumannii co-expressing OXA-23 and GES-11 carbapenemases in Lebanon. Int. J. Infect. Dis. 36: 56-61. http:// dx.doi.org/10.1016/j.ijid.2015.05.015

Khorsi K, Messai Y, Hamidi M, Ammari H, et al. (2015). High prevalence of multidrug-resistance in Acinetobacter baumannii and dissemination of carbapenemase-encoding genes bla $a_{\mathrm{OXA}-23}-$ like, $b l a_{\mathrm{OXA}-24}$-like and $b l a_{\mathrm{NDM}-1}$ in Algiers hospitals. Asian Pac. J. Trop. Med. 8: 438-446. http://dx.doi.org/10.1016/j.apjtm.2015.05.011

Kwon KT, Oh WS, Song JH, Chang HH, et al. (2007). Impact of imipenem resistance on mortality in patients with Acinetobacter bacteraemia. J. Antimicrob. Chemother. 59: 525-530. http://dx.doi.org/10.1093/jac/dk1499

Manchanda V, Sanchaita S and Singh N (2010). Multidrug resistant acinetobacter. J. Glob. Infect. Dis. 2: 291-304. http:// dx.doi.org/10.4103/0974-777X.68538

Martins AF and Barth AL (2013). Acinetobacter multirresistente - um desafio para a saúde pública. Sci. Med. 23: 56-62. http://dx.doi.org/10.15448/1980-6108.2013.1.12563

Martins HS, Bomfim MR, França RO, Farias LM, et al. (2014). Resistance markers and genetic diversity in Acinetobacter baumannii strains recovered from nosocomial bloodstream infections. Int. J. Environ. Res. Public Health 11: 1465-

Genetics and Molecular Research 15 (3): gmr.15038608 
1478. http://dx.doi.org/10.3390/ijerph110201465

Oliveira dos Santos S, Brezolin D and Hörner R (2014). Acinetobacter spp. e Pseudomonas aeruginosa resistentes aos carbapenêmicos no Hospital Universitário de Santa Maria, Rio Grande do Sul. Sci. Med. 24: 150-155. http://dx.doi. org/10.15448/1980-6108.2014.2.15809

Pagano M, Martins AF, Machado AB, Barin J, et al. (2013). Carbapenem-susceptible Acinetobacter baumannii carrying the ISAbal upstream bla OXA-51 $_{1}$-like gene in Porto Alegre, southern Brazil. Epidemiol. Infect. 141: 330-333. http:// dx.doi.org/10.1017/S095026881200074X

Peleg AY, Seifert H and Paterson DL (2008). Acinetobacter baumannii: emergence of a successful pathogen. Clin. Microbiol. Rev. 21: 538-582. http://dx.doi.org/10.1128/CMR.00058-07

Queenan AM and Bush K (2007). Carbapenemases: the versatile $\beta$-lactamases. Clin. Microbiol. Rev. 20: 440-458. http:// dx.doi.org/10.1128/CMR.00001-07

Sunenshine RH, Wright MO, Maragakis LL, Harris AD, et al. (2007). Multidrug-resistant Acinetobacter infection mortality rate and length of hospitalization. Emerg. Infect. Dis. 13: 97-103. http://dx.doi.org/10.3201/eid1301.060716

Vanegas-Múnera JM, Roncancio-Villamil G and Jiménez-Quiceno JN (2014). Acinetobacter baumannii: importancia clínica, mecanismos de resistencia y diagnostico. Rev. CES Med. 28: 233-246.

Wayne PA (2014). Performance standards for antimicrobial susceptibility testing. Clinical and Laboratory Standards Institute (CLSI). 24th informational supplement (CLSI M100-S24).

Werneck JS, Picão RC, Girardello R, Cayô R, et al. (2011). Low prevalence of bla $a_{\mathrm{OXA}-143}$ in private hospitals in Brazil. Antimicrob. Agents Chemother. 55: 4494-4495, author reply 4495. http://dx.doi.org/10.1128/AAC.00295-11

Wisplinghoff H, Edmond MB, Pfaller MA, Jones RN, et al. (2000). Nosocomial bloodstream infections caused by Acinetobacter species in United States hospitals: clinical features, molecular epidemiology, and antimicrobial susceptibility. Clin. Infect. Dis. 31: 690-697. http://dx.doi.org/10.1086/314040

Genetics and Molecular Research 15 (3): gmr.15038608 